Portland State University

PDXScholar

Dissertations and Theses

Dissertations and Theses

$11-28-1979$

\title{
Dance and Self Concept Change in Women
}

Robin Dale Anderson

Portland State University

Follow this and additional works at: https://pdxscholar.library.pdx.edu/open_access_etds

Part of the Dance Movement Therapy Commons, and the Personality and Social Contexts Commons Let us know how access to this document benefits you.

\section{Recommended Citation}

Anderson, Robin Dale, "Dance and Self Concept Change in Women" (1979). Dissertations and Theses. Paper 3007.

https://doi.org/10.15760/etd.2983

This Thesis is brought to you for free and open access. It has been accepted for inclusion in Dissertations and Theses by an authorized administrator of PDXScholar. Please contact us if we can make this document more accessible: pdxscholar@pdx.edu. 
AN ABSTRACT OF THE THESIS OF Robin Dale Anderson for the Master of Science in Psychology presented November 28, 1979. Title: Dance and Self Concept Change in Women. APPROVED BY MEMBERS OF THE THESIS COMMITTEE:
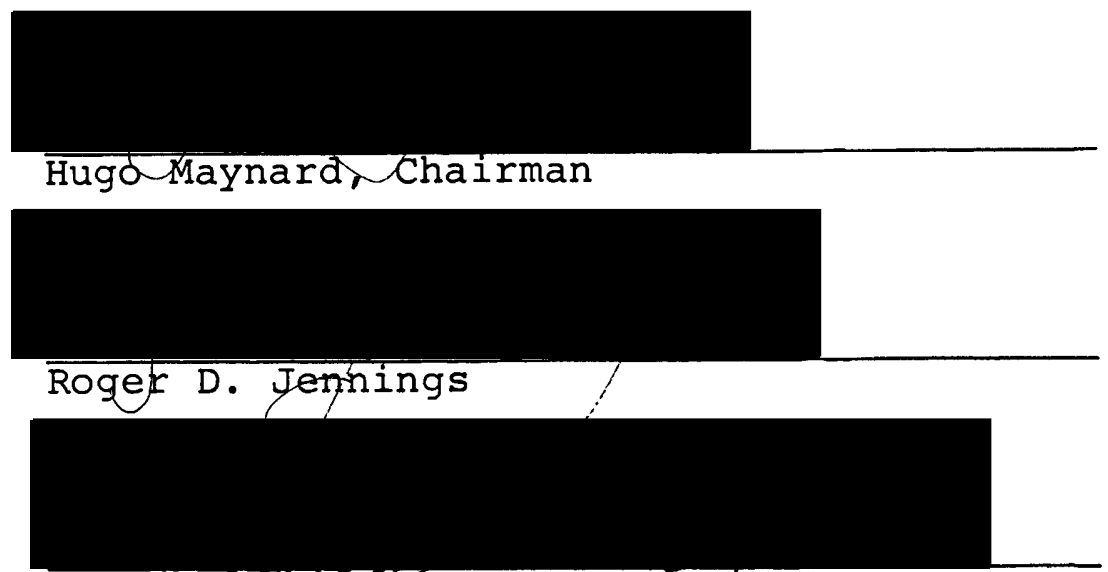

Catherine Evieshin

Numerous authors in the field of dance therapy have proposed that dance movement employed as a psychotherapeutic tool yields positive gains in mental health for participants. Self concept is frequently cited as the mechanism affecting these gains. In order to explore the relationship of dance movement alone to self concept fifteen college women were tested with the Tennessee Self Concept Scale before and after participation in a course of dance with those of ninteen women enrolled in lower division psychology courses. An analysis of covariance showed no significant changes in self concept 
scores in either group. It was concluded that self concept change is not a necessary outcome of dance training and that other variables in the therapy setting may affect gains in mental health. 
DANCE AND SELF CONCEPT CHANGE IN WOMEN

by

ROBIN DALE ANDERSON

A thesis submitted in partial fulfillment of the requirements for the degree of

\author{
MASTER OF SCIENCE \\ in \\ PSYCHOLOGY
}

Portland State University

1980 
TO THE OFFICE OF GRADUATE STUDIES AND RESEARCH:

The members of the Committee approve the thesis of Robin Dale Anderson presented November 28, 1979.

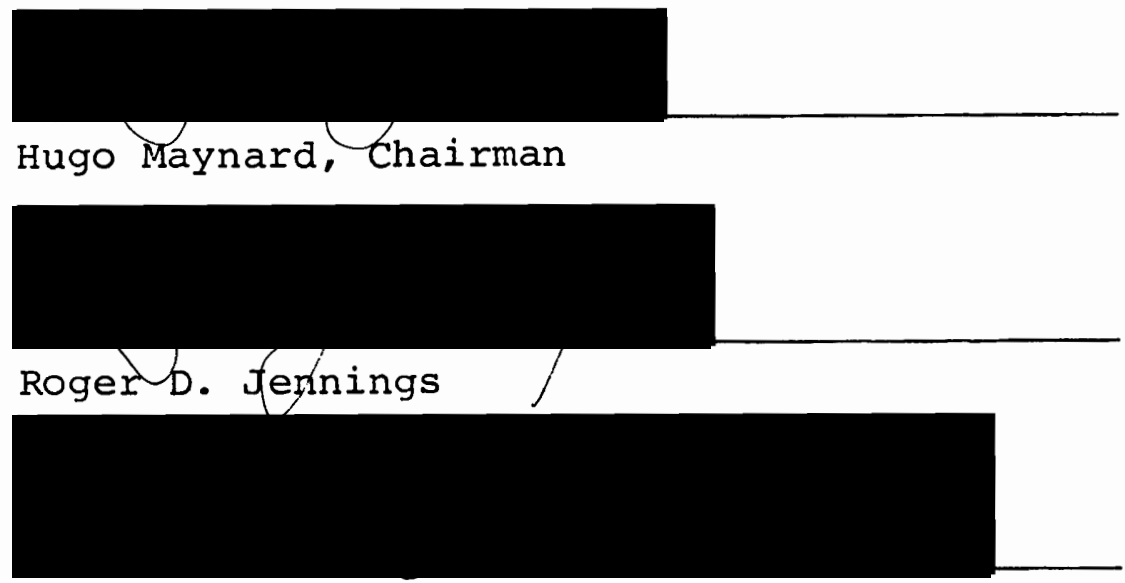

Catherine Evleshin

APPROVED :

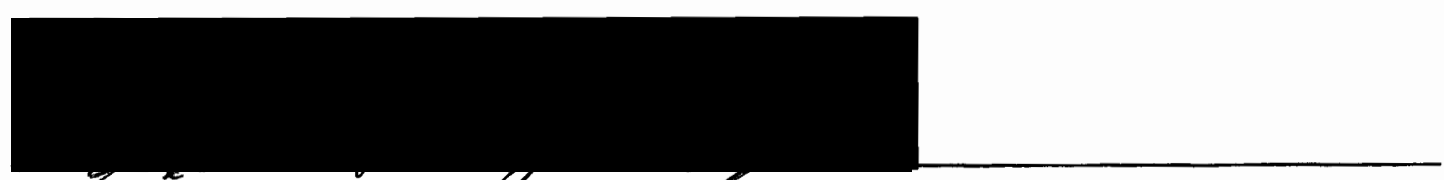

Robert Jones, Head, Department of Psychology

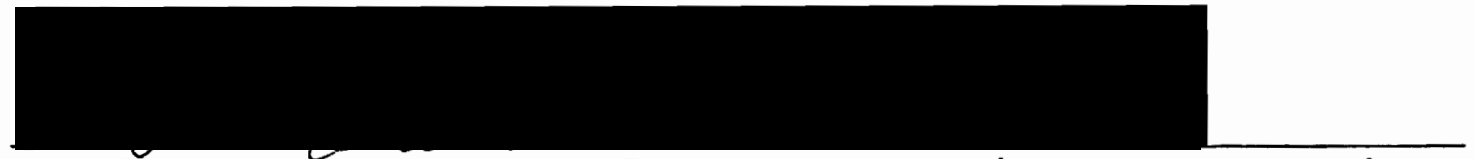

Stanley E. Rauch, Dean of Graduate Studies and Research 
TABLE OF CONTENTS

PAGE

LIST OF TABLES. • • • • . • • • • • • • • • • . • • • iv

CHAPTER

I INTRODUCTION •. . . . . . . . . . . . 1

Definition of Terms . . . . . . . . 2

Self Concept and Mental Health . . . 4

Dance and the Self . . . . . . . 13

Dance Therapy and Self Concept.. . . 20

The Present Study. . . . . . . . 32

II PROCEDURE . . . . . . . . . . . . 35

Subjects • • • • . • • . • • . 35

Recruitment and Pretest . . . . . 36

Posttest....... . . . . . . 37

Test Instrument . . . . . . . . 38

Treatment Condition . . . . . . . 40

Experimental Environment . . . . . 41

III RESULTS . . . . . . . . . . . . . 43

IV DISCUSSION . . . . . . . . . . . 46

BIBLIOGRAPHY • . . . . . . . . . . . . . . 54

APPENDIX . . . . . . . . . . . . . . 58 


\section{LIST OF TABLES}

TABLE

PAGE

I Summary of Characteristics of the Experi-

mental and Control Groups . . . . . . 35

II Mean Squares and F Scores on Fourteen

Scales of the BCS . . . . . . . . . . 44

III Dance Group Pretest Means: A Comparison

Between Lofquist's and the Present Study. 49 


\section{CHAPTER ONE}

\section{INTRODUCTION}

Recently, there has been a growing interest in psychotherapeutic methods which do not adhere strictly to the format of the "client/counselor talk session." Among the new therapies with a nonverbal emphasis are those which focus on body work such as recreational therapy, running therapy, Rolfing, Reichian body work and dance therapy. Articles have appeared in both popular magazines and scholarly journals extolling the virtues of one or more of these techniques. Descriptions of salutory experiential and behavioral changes are cited to justify the use of a given therapeutic formula. There have also been attempts to explore in more quantitative ways how or why these methods are effective.

Throughout its short history in this country, most evidence for the therapeutic effectiveness of dance therapy has been based on anecdote. Some research in the last ten years has been more rigorously experimental but there remain a number of important basic issues regarding the hows and whys of dance as a psychotherapeutic tool.

One of these concerns is whether technical dance training alone results in psychotherapeutic change. One might expect as much, for it was just such a claim that started dancers and dance teachers along the path of inquiry and 
experimentation that resulted in the development of dance therapy (Chace, 1975; Schoop, 1974). However, the question remains: Is technical dance training in itself therapeutic or is it necessary to link it with other elements, such as improvisation, self-expression, client-therapist communication or group interaction to achieve therapeutic results?.

- Exploration of this question is the major focus of this thesis.. The method will be experimental, aiming to yield quantitative results that will either verify the psychotherapeutic effects of technical training or indicate that perhaps the positive outcome of dance therapy is derived from non-movement elements. First, it will be important to define the terms "dance", "technical dance training", "dance therapy", and "positive psychotherapeutic outcome". Next, ideas in dance and dance therapy literature concerning the psychologically healthful effects of dance will be examined. Finally, other writings, dealing with body movement and its influence on body image and self concept, will be explored. These will provide some explanations of the success of dance as a psychotherapeutic tool. A survey of these sources will provide the background for the present exploration of the beneficial effects of technical dance training.

Definition of Terms

For the purpose of this thesis, dance will be defined 
as successive, rhythmic bodily motions, sometimes performed with music. Dance may be spectacular (e.g., a ballet staged before an audience), recreational (e.g., disco dancing at a night club), or ritualistic (e.g., sacred tribal dances of certain North American Indians). The overall goal of technical dance training is to teach one to dance. This may occur in a variety of styles (ballet, modern, jazz, tap, etc.) but the universal effect is to orient the student to movement in a certain mode and to guide her in the practice of that movement. The particular focus in technical training is on externals, that is, the physicality of the dancer. Initial attention is given to strength, flexibility and endurance. Later, emphasis is placed on body awareness and fine muscular control of body parts. Finally, as the dancer becomes more capable, the focus is on coordination of the various body parts in specific movement patterns. - Little attention is paid to the personal frame of reference of the individual: emotional state, interpersonal relationships, past experiences and so forth.* The orientation of technical dance training, thus, tends to be outward.

\footnotetext{
*It would be a mistake to say that these elements never enter into the dancer's world, but they seem more likely to be present in the creative areas of dance: improvisation and choreography. There are a number of instructors who will examine these elements with their students but this is generally done outside of the conventional technique class.
} 
- Dance therapy is the use of successive, rhythmic bodily motions to bring about therapeutic, specifically psychotherapeutic, change. Among the various dance therapy techniques there are common elements. A major similarity is the inward focus. Of course, bodily movement being what it is, one can never become completely removed from physicality. There is, however, a deemphasizing of the external. More accurately, there is a balancing of attention given to inner and outer states, a striving for wholeness. The dancer becomes more than a body; she becomes a "self.".

Positive therapeutic outcome is usually defined in terms of some specific criteria that can be readily measured. For this reason, positive psychotherapeutic change will be defined in this thesis as a positive change in self concept as measured by the Tennessee Self Concept Scale (TSCS).

Self Concept and Mental Health

- Self concept is the set of perceptions, beliefs and/or assumptions that an individual holds to be true of her/himself: According to adherents to self theory, the picture of the self is one of the few stable features of the individual's total phenomenological environment. It is the frame of reference through which $s /$ he interacts with the world. . 
There are a number of conceptual systems which may be classified as self theories and each of these provides a different view of the development of self concept. William James' (1890) theory of the consciousness of self is forerunner to many. He describes four aspects of the self: the material self, the social self, the spiritual self and the pure Ego. (See Chapter $X$, The Principles of Psychology, 1890.) A comprehensive review of various self theories can be found in Chapter 13 of Hall and Iindzey's Theories of Personality (1970, pp. 515-523.)

Self theories share some common principles. First, they agree that the self concept is not innate but a developmental phenomenon. Second, they agree that the self concept is based on a differentiation of one's self physically and perceptually from the environment (James' material self). This basic "self" is later modified by social interactions, particularly those involving "significant others" (James' social self and spiritual self). Finally, there is a consensus regarding the paradoxical stability of self concept once it is developed and its apparent changeability (James' pure Ego). All of the self theorists place the self at the center of the individual's being, and include self-perception as an important component. If this is the frame of reference through which the environment is experienced, it is bound to have overwhelming influence on the person. 
Research by self theorists has demonstrated the vital role played by the self in psychotherapy. Raimy (1971) devotes much of his discussion of self concept to its role in the counseling process. He maintains that when a psychotherapeutic situation results in personality reorganization a comparable restructuring of the self concept occurs. Conversely, if there is no reorganization of personality, structural relationships within the self concept remain unaltered. Raimy goes on to say that this altering of self concept in a therapeutic context will result in ". . . increased 'feelings' of comfort and effectiveness, and the reduction of 'feelings' of discomfort and ineffectiveness" (pp. 117-118). In addition, there is a lessening of the frequency and intensity of "disorganizing emotionalized processes" (p. 151).

On the basis of his research on the role of self and self concept in psychotherapy, Rogers (1961) has concluded that changes in the perceived self seem to be greatest during therapy. He also found that changes in the perceived self of the client were in directions that psychologists termed "adjustment." In addition, there is a significant increase in congruence between the client's perceived and ideal self. (The client's representation of her ideal self remains the same through the course of therapy, discounting the possibility that increased congruence is due to an alteration of the ideal self.) Finally, Rogers (1961, p. 237) asserts 
that the self picture ". . becomes a more accurate representation of the totality of experience" and the client, in turn, becomes less defensive.

To explore more specifically the relationship between self concept and mental health it is important to ask two related questions. Based on the above research, one might postulate that self concept and mental health are highly correlated in a positive direction. One then needs to ask if, in fact, high self concept indicates good mental health and inversely, if good mental health indicates high self concept. Good mental health, for the purpose of this discussion, will be defined as the "self-actualizing" and "fully functioning" persons of Maslow's (1954) and Roger's (1961) respective theories. The second question is concerned with the opposite proposition. That is, is it ncessarily true that low self concept implies poor mental health and that poor mental health betokens low self concept? All of the evidence presented in this paper to establish this relationship is based on research with individuals who have been assigned a psychiatric diagnosis. Therefore, poor mental health will be defined as experience and/or behavior that leads to acquiring a psychiatric diagnosis. It is important to note that such a criterion should be subject to the reservations discussed by Fitts (1972, p. 3).

Fitts (1972) summarizes a large body of research in 
which measurement with the Tennessee Self Concept Scale is used. He folund that persons who score high on personality integration (PI) also score high on self concept.. Fitts, summarized his results as follows:

1. They [persons with high PI scores] have high self esteem. The great majority of them score well above the mean on the $P$ (Positive) Scores.

2. They have less internal dissonance, contradiction, or conflict in their self concepts.

3. They show less variability in self-perception across the various subselves.

4. They have fewer deviant and pathological features in their self concepts.

5. They show less acquiescent response set in defining their self concepts.

6. They are neither extremely defensive nor lacking in defenses in reporting their self concepts.

7. Their self concepts are neither extremely certain nor uncertain. (1971, pp. 76-78.)

In other studies, high PI individuals tend to be rated higher than the average on experiences and behaviors which are reflective of good mental health. For example, high PI persons report both positive and negative experiences but appear to be able to utilize these in such a way as to make themselves open to continued experiencing. These persons also demonstrate a higher rate of behavioral competence, as perceived by themselves and others, than individuals who do not obtain high PI scores.

Two studies particularly concerned with this aspect of mental health and personality integration are those by Duncan (1966) and Seeman (1966). Administering basically the same treatment condition to two different subject pools 
(men and women) the authors found that those who were selected by peers for high behavioral competence also received high scores on self concept.

Fitts (1971) also cites a number of studies which positively correlate high self concept with warmth and openness in interpersonal relationships, greater environmental contact, higher intellectual efficiency and more adaptive cognitive, perceptual and physiological functioning. Thomas and Seeman (1971) found that high PI individuals were more able to use cognitive resources to deal creatively with other people. They also demonstrate ". . a capacity for empathetic relationships with others, as well as a selfacceptance and self-satisfaction that provides for inner and behavioral stability." (p. 29)

Finally, Tolor, Cramer, D'Amico and O'Marra (1975) found self concept to be related to psychological distance in women. They discovered that high self concept subjects maintained a closer psychological distance with eight different social objects (models that the subjects were asked to imagine to be "mother", "boy friend", etc.) than did low self concept persons. Tolor, et al., also substantiated a highly significant tendency for low self concept and high self disclosure individuals to withdraw from the experiment before completion while high self concept and high self disclosure subjects demonstrated the opposite trend. This 
led to the conclusion that being a confider with a low self concept inclines one to withdrawal behavior much more frequently than one who is a confider with high self esteem. These findings correspond to Rogers' (1961) theoretical assertions concerning the behavioral and experiential nature of the mentally healthy or "fully functioning" person. He maintains that such an individual is open to her experiences. The individual becomes less defensive, less fearful of emotional outburst and is willing to operate in a way that permits emotions to emerge.

Maslow's (1954) projected role of self concept in the self-actualizing individual is also relevant. This person is self-accepting, lacking unnecessary shame without being smugly self-satisfied. The self-actualizing individual sees reality more clearly than those who are unhealthy and accepts his shortcomings and strengths equally. There is acceptance of self on the physical level reflected in a healthy appetite for food, sex, and exercise, and on a social level with an absence of defensiveness and a distaste for deceit, hypocrisy and artificiality.

It appears, then, that persons possessing good mental health are also likely to possess high self concepts. The question that remains is whether persons with poor mental health manifest low self concepts.

Fitts (1972) did extensive research exploring the relationship of self concept to various psychiatric diagnoses. 
His findings, reported in detail in his monograph The Self Concept and Psychopathology, are briefly summarized here. One significant discovery was that the medians on various subscales of The Tennessee Self Concept Scale for different diagnostic categories indicate a trend toward low self esteem in all areas for psychiatric patients. The groups have consistently high scores on scales indicating pathology (Number of Deviant Signs, General Maladjustment and Neurosis) and low scores on Personality Integration. Further, detailed analysis led Fitts to draw the following conclusions:

1. Persons with permanent brain damage show the greatest conflict and confusion in their self concepts.

2. Manics, who exhibit such grandiose behavior, also have grandiose self concepts and show much higher self esteem than any other group.

3. The Emotionally Unstable Personalities. . . have the lowest level of self esteem.

4. Those categories whose behavior is most distressing to others . . . also view their own behavior negatively.

5. A sense of moral-ethical worth is . . . stoutly maintained in most Psychoses and Neuroses but uniformly denied in the Sociopaths, whose moralethical behavior is so objectionable to others.

6. The groups characterized by erratic, inconsistent external behavior . . . are the ones that have the most variable and internally inconsistent self concepts.

7. The most mildly disturbed show the highest level of personality integration and the most acutely disturbed have the lowest level. ( $p$. 112)

To summarize, deviant measures of self esteem (either very low or extremely high) reflect and are associated in systematic ways with psychiatric symptoms, antisocial behavior and ineffective, maladaptive behavior. 
Two related studies also demonstrate the tendency to have low self concept in individuals who have poor mental health or who engage in what is characteristically labeled by society as deviant behavior. The first of these, a study by Gross and Adler (1970), reports on the self esteem of alcoholics. For the nine measures of the Tennessee Self Concept Scale used, the alcoholic group scored significantly lower (i.e., in the direction of low self concept) than the test standardization group. In addition, scores on the self criticism scale showed that alcoholics tend to be more open and self-critical than the norm.

The second study by McPartland, Cumming and Garretson (1961), looked at patients' ward behavior in psychiatric hospitals to find out if differences in self concept could be used to predict future behavior. They were able to do this with a high level of consistency for behaviors termed withdrawn, restless, extravagant, pleasant and well-socialized. Moreover, they discovered that persons whose self concept was reported predominantly in either physical or highly abstracted terms behaved in a withdrawn or bizarre manner while those who reported themselves in more conventional, social terms were characterized by predominantly pleasant, well-socialized behavior.

Snygg and Coombs (1949) explain the dynamics of neuroses and psychoses in terms of the phenomenal self, the core of which is the self concept. They maintain that if some 
aspect of the phenomenal self is threatened by either external events or internal perceptions of behavior, the self concept may be unable to accommodate. The threatening perceptions are then suppressed but continue to motivate behavior and endanger the self. The individual may then begin to behave or experience the world in bizarre or frightening ways in order to guard against the threat to the self concept. This way of existence may be thought of as being diametrically opposed to Maslow's (1954) selfactualizing person whose contact with reality (i.e., the phenomenal environment and self) is so solid and suggests a substantially different self concept.

Hence, in exploring the relationship between self concept and mental health one finds it to be generally demonstrated in theory and research that a positive self concept indicates a mentally healthy individual. The exception is mania where self concept is abnormally high. Observations made in therapy bear this out. The opposite seems also to be confirmed; low self concept is characteristic of the maladjusted person. In returning to the principal issues of this paper, it will be important to keep this relationship in mind. It will provide one essential justification for the use of dance as a psychotherapeutic tool. Dance and the Self

References to the connection between the self and dance 
are found throughout dance literature. Dancers and choreographers as well as dance academicians (historians, educators, anthropologists) have noted the wide reaching effects of dance. In any field of endeavor the evaluations and conclusions reached by practitioners of that discipline have a slightly different emphasis than those of the observer. The practitioners of dance tend to reach to subjective material and base their most emphatic statements about dance on introspective or immediate external observations. Those who interpret the activities of the practitioners of dance with respect to some independent frame of reference, color their observations with the tenets of that interpretive framework. Yet, it is not difficult to tease from these richly varied observations, the assertion, assumption or insinuation that dance movement, in any of its forms (recreational, ritual, spectacular), is intertwined with the inner essence of humankind.

Doris Humphrey, a pioneer in modern dance, stated: "At all times we must be aware that the dance art is unique in its medium of movement. Unique too is its power to evoke emotion within its vocabulary . . to speak of the subtleties of the body and the soul." (1959, p. 34) Dance may tell the dancer or observer about themselves, reveal their self-perception. She also recommends that the choreographer develop the quality of a " . . keen observer of physical and emotional behavior . . " (1959, p. 20) In order to make 
dances one must be in touch with the way in which people reveal themselves and know the best ways to show the self in order to communicate in performance that which is intended.

Communication of emotion is a recurrent theme in the writing of some choreographers. They maintain that emotion is the source from whence movement flows. Sokolow (1965) notes that movement is evoked by emotional images and that intellectual processes only enter the choreographic art at the point of forming the spontaneous movements into a cohesive unit. Dance, she says,". . is not intellectual. It deals with deep emotion." (p. 30) Dance, then, is often created by emotional images or states, and organized by intellectual processes in order to communicate intelligibly that image or state to the observer.

of course, this is not to say that every dance performance is a massive display of the inner beings and emotional states of its choreographer(s) or performer(s). It is only to make the point that the self, especially the emotional self, may be the source of the movement that one sees. In creating a work the choreographer may have tapped these resources. In developing the proper dynamics and movement quality for performance, the dancer was probably called upon to touch similar veins in herself. Suzanne Langer (1970) terms this process virtual self-expression. That is, although it may appear that the dancer is revealing 
her emotional state, she is actually employing gestures that are symbolic of that state. "It is imagined feeling that governs the dance, not real emotional conditions." (p. 27)

The observer may be touched by these symbolic gestures. Response to them may reveal something of the self to her (through introspection) or to others (through expressed reaction). Pauline Koner (1965) states ". . in intrinsic dance true identification is possible. Its movements, though stylized, are not so removed from the movements of living, and the audience can relate to a human experience." (p. 83) This communication of self through movement is found in dance forms other than spectacular. Dance academicians have made a special contribution through observation and evaluation of recreational and ritual forms of dance and exploration of the question."Why do we dance?",

To answer this question academicians usually begin by turning to the primitive uses. of dance. "Primitive" here is defined as those cultures not advanced technologically, those which maintain(ed) a hunting or simple agricultural society, or as the movement of young children..

Dance in primitive cultures fulfills many functions. Richard Kraus (1969) lists five: Dance ". . is used as a means of worship, as a way of expressing and reinforcing tribal unity and strength, as a framework for courtship or mating, as a means of communication, and as a therapeutic; 
or healing experience." (p. 16) of special interest here are the building of tribal unity and the therapeutic qualities of dance.

Kraus (1969) notes that dance became a primary means of social identification. It was one of the means whereby the young child learned the tribal lore and customs and later, as a participant, felt and expressed a oneness with the group. Within the social framework of the tribe it was the purpose of dance to establish ". . social unity and provide a means of collective strength and purpose." (p. 10) Hence, dance helped the individual to find her place in relation to the tribe and to the world.

In his discussion of the social functions of dance among the Kwakiutl Indians of Vancouver Island, British Columbia, Boas (1944) notes that ". . practically every aspect of Kwakiutl life is accompanied by some form of dance - ." (p. 5) There are highly developed systems of both sacred and theatrical dance. Any activity that is constantly present in the life of an individual may be thought to exercise influence in the development of that individual's self concept. It would seem apparent then, that dance is a shaper of the self concept of a Kwakiutl Indian.

Dance not only played a role in establishing the self concept of primitive peoples, it was also an important tool in restoring that self concept in times of illness or despair. Meerlo (1962) notes that people have long been aware 
of the cathartic and creative properties of dance and of its value in alleviating boredom and frustration. He further states that ". . dance of medicine man, priest or shaman belongs to the oldest form of medicine and psychotherapy in which the exultation and release of tension was able to change man's physical and mental suffering into a new option on health." (p. 24)

Gorer (1944) provides examples of this in his discussion of the function of dance in various West African tribes. He states specifically that "Sorcery dances are used for therapy and policing, and like the activity of the medicine man are used according to the amount of sickness and misfortune." (p. 39)

Tribal man makes deliberate use of dance. The purpose of rythmic movement in technological societies is less obvious but just as far-reaching. Horst (1961) asserts that r we all use movement instinctively to express feelings, both positive and negative. This is particularly evident in the movement of children..

According to Gladys A. Fleming (1976) "The opportunity to use movement is as expressive for the child as it was for primitive man. Through this medium the child can react to the world around him, use it as a means of communication, and express the thoughts and feelings that are deep within him." (p. 20) . Movement is the first language of childhood.It allows the child to learn about the environment through 
direct contact with it, to communicate with other human beings and to express her views and emotions including those concerning herself and her place in the world.

Dance is not only important during childhood.. Meerlo (1962) traces the role of bodily movement through the human life, neonate to mature adult. These constitute the dance of life. They are the expressive movements that serve the same purposes in adulthood (if not suppressed) that they did in childhood. He emphasizes the health-promoting qualities of these dances.

- Remaining expressive in one's everyday movements promotes and indicates a healthy individual., Carrying this expressiveness into a dance form (recreational, ritual or spectacular) is doubly therapeutic. Meerlo (1962) believes that dance allows the individual to rediscover her body as an expressive tool. He goes on to state that ". . when man wants to become joyous and unworried again as he once was in childhood, when man wants to laugh at his selfdestructive strivings . . . then man starts to dance." (p. 42) Dance, then, gives the individual an opportunity to alter the way she perceives herself and the surrounding world. It permits a change in self concept.

Martin (1965) suggests that dance is able to promote an altered self image because, as with other forms of art, it ". . provides an extension of the emotional potentialities, leading to easier adjustments, larger tolerances, 
broader visions." (p. 41) He also suggests that in dredging up and synthetically satisfying half-felt needs and wishes in an imaginative mode an important step is taken toward fulfilling those needs in reality.

H'Doubler (1962) reiterates this idea, asserting that from the deprivation and fulfillment of day-to-day life we build a vision of "how things ought to be." Dance affords us an opportunity to experience these ideals. We are able, through the medium of movement, to experience our ideal selves.

Dance, then, to dance artists and academicians is not just an external phenomenon. Nor are its internal qualities confined to the proprioceptive sense. Dance can have emotional and spiritual import. The realization of these qualities led to numerous observations on the state of those individuals who cannot move expressively. Meerlo (1962) states it most succinctly (although a bit harshly): "Those who cannot dance are imprisoned in their own ego and cannot live well with other people and the world." (p. 39) From similar observations and later experimentation with dance movement as therapy with disturbed individuals, grew the field of dance therapy.

\section{Dance Therapy and Self Concept}

When dance was taken from the theatrical or recreational setting and placed in a clinical one, two things happened. 
First, it was implemented in a new way, as a psychotherapeutic tool. Second, a systematic collection of data was begun to verify those assumptions that brought dance into the clinical realm in the first place. A cursory review of the populations sampled, data gathering methods and obtained results will indicate the stage at which dance therapy as an experimental science finds itself. Observations, experimental and otherwise, specifically concerned with dance therapy and self concept are particularly pertinent to this study and will be explored. Additional research done by non-dance therapists and relating to movement and self concept provides possible explanations for the effectiveness of dance as a psychotherapeutic tool. All of the factors indicate potentially fruitful paths of inquiry for further research.

Initially, dance therapy was done primarily with institutionalized, adult, psychotic patients (Chace, 1975, Rosen, 1957). Programs were later developed for children, both disturbed (Gunning and Holmes, 1973; Siegel, 1973) and normal (Salkin, 1973; Fleming, 1976). Dance has also been employed with mental patients who have physical handicaps such as deafness (Robinson, 1973) and with mentally retarded children (Canner, 1968; Salkin, 1973). Finally, dance therapy programs have proven effective with "normal" adults (Pesso, 1969). 
Administration of treatment and outcome criteria varied throughout the studies while method of evaluation was mostly subjective. One-to-one sessions (Seigel, 1973) and group experiences (Pesso, 1969; Sandel, 1975) have both proven effective in eliciting healthful responses from clients.. Goals for outcome depended on the initial condition of the patient. In extremely withdrawn persons a move toward greater social contact was viewed as a healthful response (Rosen, 1957; Levy, 1974). In persons who were able to manage the rudiments of daily living, additional insight and coping with specific problems was considered an improvement (Alperson, 1974). Most evaluation was done by the therapists although occasional commentary by physicians and psychatric care nurses was included. Patients' reports of an increase in feelings of well-being supported the observations made by therapists (Rosen, 1957). In all of the earlier studies (1950's and 1960's) and in a large portion of the more recent ones, evaluation was based on the observations of those involved in the therapeutic situation (Rosen, 1957; Siegel, 1973; Alperson, 1974). No standardized tools of psychological assessment were employed. A notable exception is Lofquist's (1979) use of self concept measures. Also worthy of mention is Gunning and Holmes' (1973) development of a 19-point scale to measure components of body movement in psychotic children. 
Claims concerning changes of personality and behavior affected by dance therapy are numerous. Rosen (1957) focused attention on the socializing, tension relieving and communicative qualities of dance. She stated that "Self expressionism (sic) . . . is consciously encouraged in the patient, since the emphasis in therapeutic dance is on spontaneous response as a direct form of social communication." (p. 46) She further observed that dance provided a medium ". . for the expression of such emotions in a socially acceptable and sublimated form and can therefore be viewed as a means of releasing tension." (p. 4)

These tenets have since been reiterated and expanded by others. Fleming (1976) stresses the communicative aspects of movement with a developmental focus. Movement, she says, is ". . a nonverbal, dynamic form of expression and communication." (p. 33) It serves to teach the child about his environment and provides a tool for the expression of thought and feelings. Salkin (1973) emphasizes communication also and notes that such expression ". . through movement brings about much relief, satisfaction and a sense of well-being." (Foreword, p. xi) Sandel (1975) states that group dance therapy constitutes ". . a shared emotional experience that forms the basis for relationships with others - ." (p. 440) and improved social contact.

Additional factors which appear to be affected by dance therapy include Siegel's (1973) noted improvement of reality 
testing and problem-solving abilities in phobic patients. After examining the aforementioned studies, it is apparent that the main body of research in dance therapy has been done in the style of natural history. This method seems the most logical and prudent to pursue given the newness of the field, the nature of the populations involved and the primary importance of refining the therapeutic technique. To attempt research with complicated experimental design and rigorous controls would have been inappropriate. However, it appears that enough field observationial data has now been collected to warrant research based on experimental method. There have, in fact, been a few studies (Ludwig, 1971; Hann, 1973; Lofquist, 1979) which introduce experimenter manipulation in a dance/dance therapy situation. They deserve more detailed treatment here because of their use of experimental method and, more importantly, becaluse of the questions they raise about doing research in dance therapy.

! Hann (1973) compared dancers (defined as someone who had istudied modern dance technique for three or more years) with non-dancers on self-image, body-image, movement concept and $\mid$ kinesthetic arm positioning. She used secord and Jourard's Self-Cathexis and Body-Catherxis Tests, Nelson and Allen's Movement Concept Test and a kinesthetic arm positioning test which she had devised to examine the above factors. Results showed a difference between the two groups 
on movement concept only. As regards the self-image and body-image factors the experimenter felt that it was possible that a dancer might be critical of her body as a result of her dance training which would counteract a higher body-image score, accounting for the lack of difference between the two groups.*

This study fails to do two things which seem critical in determining if dance does indeed promote an altered selfimage. First, it does not consider that the individual who decides to follow three or more years of dance training and the non-dancer may have highly divergent self concepts prior to the introduction of the dance factor. Second, by sampling the groups at only one point in time it does not tap a factor that is particularly relevant to the issue of dance as a psychotherapeutic tool. That is the element of change.

Ludwig's (1971) study does deal with the change-overtime factor. She tested 30 female subjects for creativity, coordination, abdominal strength, leg strength, balance, dorsal-ventral flexibility and self-image. Self-image was

\footnotetext{
* The body aesthetic for modern dancers in this country today is one of slenderness and strength. This aesthetic is conveyed both verbally and nonverbally in dance classes of all levels. If a dancer feels she is not slender or strong enough her body-image may be poor in spite of the fact that she is in excellent physical condition.
} 
measured with the Interpersonal Check List. Half of her subjects served as a non-dancing control group while the other fifteen were involved in a beginning-level dance class. The experimental group was drafted after subjects had signed up for the class. All participants were examined before and after the ten-week experimental period. The results did indicate a slight alteration in the self concepts of the treatment group subjects. However, it was not statistically significant. A possible explanation for the lack of statistical results can be found by comparing the above study with Lofquist's (1979).

Lofquist (1979) administered the Tennessee Self Concept Scale (TSCS) to a group of middle-aged, female volunteers, all interested in taking part in a free dance class she was offering. None of the subjects had previous dance training. The group was divided in half and dance lessons given to one group while the remaining subjects functioned as a non-dancing control group. (After the conclusion of the experiment, the control group was offered a similar class.) At the end of a ten-week period she retested both groups.

The treatment condition consisted of sessions similar to beginning level jazz dance classes given once a week. The format involved regular warm-up exercises and simple acrossthe-floor movement patterns of "steps." Music was used as an accompaniment to both. In addition, Lofquist verbally 
emphasized the beneficial qualities of each exercise and explained how each would effect the body. She encouraged the participants to notice the strength and beauty of their own bodies as they did the exercises. She also attempted to engender a non-competitive view of the class situation and the idea that the sessions would prepare the participant for further dance instruction elsewhere. Subjects were not allowed to improvise movement in the classes.

Retest showed that the control group subjects' self concept scores on the TSCS had not changed significantly over the ten-week period. The experimental group showed significant gains in self concept on Total $P$, that is, on overall self image $(F=5.75, p .05)$, and on sub-scores for Physical Self $(F=7.86, p .01)$, Personal Self ( $F=3.50, p .05)$ and Behavior $(F=8.25, P, 01)$. There was no significant change on the remaining measures of the TSCS.

While it is clear that a change in self concept in a healthy direction did occur in the dance group, the factor affecting the change is uncertain. Was it the movement itself, the encouragement and positive regard supplied by the experimenter, or both? Is dance movement alone enough or are other components in the group interaction necessary to foster self concept and psychotherapeutic change? What role does music play in the therapeutic scheme? Worthy of consideration when comparing Ludwig's and Lofquist's results is the efficiency of the self concept 
measures employed. It is possible that the TSCS is better suited to registering the changes that occur as a result of the dance experience than is the Interpersonal Check List. Possibly the most important achievement of the three studies described here is the fact that they begin to explore the relationship between dance and self concept. Although a number of the studies cited earlier hint at the role self concept might play in therapeutic change engendered by dance, none attack it directly. Hann, Ludwig and Lofquist have all taken a cue from dance literature in choosing to explore self image and dance. There are further indications in dance therapy literature of the fruitfulness of such a path of inquiry.

Early in the development of dance as a psychotherapeutic tool, Lawton (1949) noted that dance is ". . a therapeutic agency . . quite unparalleled in potentialities. This is so because dance addresses itself to the whole individual; physical, mental, emotional, spiritual."* (p. 134)

Schmais (1974) observes that dance allows the individual to begin at her own physical and emotional level and from thence provides ". . experiences that foster growth and

\footnotetext{
"Note the similarity to William James' description of the aspects of the Self in Chapter $X$ of Principles of Psychology, Dover Publications, 1890 .
} 
extension of self. . By helping to produce integrative patterns of moving, it serves to enhance the body image and to develop a sense of identity." (p. 11)

Burton (1974) maintains that for the rospitalized individual to become what is regarded as "normal" she must make a number of changes. Part of these changes are in the area of self concept. "They [patients] dislike themselves because they contrast their present behavior with their idealized self concept." (p. 22) Dance, Burton feels, helps to strengthen the individual's self esteem and is especially effective with those experiencing difficulty with body image.

It is interesting to note that the manner in which dance is thought to effect change of self concept in the disturbed adult is paralleled by the importance of body movement in childhood. Mittleman, in Rosen (1957), asserts that the development of skilled motility is an important source of self esteem in the child. In addition, it serves the important function of allowing the youngster to relate actively with other humans and the environment, to identify with the activities of other humans through imitation and to express emotion nonverbally.

Salkin (1973) stresses the importance of self concept (which she calls "identity") and further links it to body image. She cites Wexler as stating that ". . body image seems intimately linked with the problem of personal identity 
which is so central to the psychological stability of the organism." (Foreword, p. xi) She goes on to state that it is necessary for the developing infant to have movement experiences in order to stabilize body image and identity.

It appears, then, that there is abundant observational evidence for the efficacy of dance in producing self concept change. Although little explanation of the mechanism which triggers this change is provided in dance therapy literature, a factor is mentioned which likely plays an integral role. That is the element of body image.

It is important at this juncture to establish the connection between body image, self concept and dance for it provides a simple model which further validates research done in the area of dance and self concept.

That body image is related to self concept was experimentally tested by Secord and Jourard (1953). Using bodyand self-cathexis scales to determine degree of satisfaction and a homonym test to measure anxiety, they found that there was a moderate positive correlation between body- and self concepts. There was also a significant negative correlation between body-cathexis and body anxiety for women, indicating that those with poor body image maintained a corresponding high anxiety regarding body parts and functions.

In related research, zion (1965) measured subjects on three facets of body image and three corresponding aspects of self concept: description, acceptance and ideal. A 
fourth "discrepancy" score was calculated for differences between description and ideal on both concepts. When scores were correlated across the two dimensions significant linear relationships were found.

Schilder (1950) devotes much of his discussion of body image to the influence of motion and posture. He claims that physical movement alters body image. "Tension and relaxation of muscles, moving the body with and against gravity, with and against centrifugal impulses may have an enormous influence on the body image. The phenomenon of the dance is therefore a loosening and changing in the body image." (p. 207) He further asserts that the altered body image is accompanied by a change in "psychic attitude" or inner feelings including those about the self. Thus, in Schilder's view, dance may directly affect the psychic attitude.

There is, then, experimental support for the link between self concept and body image. This provides a viable explanation for the healthy being promoted by dance which has been observed by dancers and dance therapists alike. What is needed now is further experimental exploration in this area; initially in the manner of the Hann, Ludwig and Lofquist studies. Such a step seems necessary in order to answer some of the questions and to solve some of the methodological difficulties of the studies. Later, more rigorous 
experimental controls may be introduced allowing more complex relationships in the area of dance and self concept to be examined.

The Present Study

Considering the work that has been done up to this point and the questions that it raises, there are several directions which a study might take to explore the relationship between technical dance training, dance therapy and self concept. First, a study to determine which of the available self concept scales is most effective in measuring change in the dance situation seems necessary. A strong, dependable test instrument is crucial to continued research. If a satisfactory measuring device cannot be found among those which are currently in use, individuals exploring this area may find it necessary to construct one which will suit their needs. Second, possible differences between the initial impact of the dance training or dance therapy situation and later effects need to be examined. At what point in either of these experiences is the optimal level for a change in self concept reached? Might not this point in time vary for different subject populations? Third, which components of the dance therapy situation are genuinely therapeutic? Is the dance movement itself responsible for improved mental health or would any form of physical action (or any other activity) be as 
beneficial? What is the role of non-movement aspects of the dance therapy experience in promoting mental wellbeing?

The options for research are seemingly endless and further enumeration is unnecessary. The listing above simply demonstrates that ground work must be done in order to provide a foundation which will support more complex studies. It is beyond the scope of a Master's Thesis to attempt to explore all of these questions.

What I propose to do here is to examine further the territory explored by Ludwig and Lofquist. This will be accomplished by employing Ludwig's basic design, deleting tests for creativity and physical abilities, and using Lofquist's test instrument. Loquist did find a change in the self concepts of her treatment group. This may indicate that her test instrument is more sensitive to those changes occurring in the dance situation than was Ludwig's. It is also possible that the confluence of dance and nondance variables in Lofquist's procedure accounted for the change. Ludwig's results are clearly based on an experimental situation which did not involve these non-dance variables. However, her use of the Interpersonal Check List may have affected her results.

Combining these two methods by introducing a dancenaive subject group to a technical dance training condition and testing with the TSCS, I hope to reach a clearer con- 
clusion concerning the ability of dance training alone to promote a change in self concept. 
CHAPTER II

PROCEDURE

Subjects

"Subjects were sixty-six Portland State University students; 52 women and 14 men. Participation was voluntary. Age ranged from 17 to 43 years with a mean age of 22.7 years and a modal age of 18. A $35 \%$ attrition rate resulted in a final $\mathrm{N}$ of 43 . Sixteen subjects remained in the treatment condition ( 15 women and 1 man) and 28 remained in the control group ( 19 women and 9 men). It was decided that in order to increase the comparability of the 2 groups all males would be dropped from the sample. This left a total $\mathrm{N}$ of 34 . The two final groups showed the following statistics:

\section{TABLE I}

SUMMARY OF CHARACTERISTICS OF

THE EXPERIMENTAL AND CONTROL GROUPS

EXPERIMENTAL

$$
\bar{N}
$$

15

CONTROL

MEAN AGE

21.1

23.8

MODAL AGE

18

19

AGE RANGE

18 to 34

18 to 43 
Recruitment and Pretest

Subjects for the treatment group were recruited from three beginning level, modern dance classes.. On the first meeting day of the term the experimenter attended the classes from which volunteers were to be drawn. As arranged previously with the dance teacher, the experimenter was introduced as a graduate student in the Dance and Psychology Departments. The experimenter then gave a short introduction as follows:

I am looking for volunteers to take part in a study I'm doing through the Dance and Psychology Departments. Participation will consist of answering 100 questions concerning how you feel about yourself on a survey. You'lil be asked to take the survey once now and again in eight weeks. Your individual answers and test scores will be confidential. If you wish, you can obtain those scores from me at a debriefing session which I will schedule after the second testing session. I would like to have as volunteers, those individuals who have not had dance training during their adult life. If you are between 18 and 22 and you did take dancing lessons when you were younger, I would like it to have been at least five years since you had those lessons. Please remember that if you do take part in this study and you feel at a later date that you would like to drop out, you will be perfectly free to do so.

Those students agreeing to be experimental subjects

were tested immediately with the Tennessee Self Concept Scale (TSCS)." The test appears as Appendix 1. Time permitted the volunteers to be tested immediately as the first day of a beginning dance class is used only for verbal introduction. After taking the test, volunteers were told again that they would be contacted at the end of the eight 
weeks to be retested.

Control group subjects were recruited from lower division psychology courses. At the beginning of the class meeting time the instructor introduced the experimenter to the class as a graduate student. The experimenter then made the same introductory comments as had been given to the dance classes. In addition, control group subjects were asked to take part in the study only if they were not enrolled in a dance class that term. Rather than testing immediately, a number of times and meeting places were given and anyone interested in participating was requested to attend a testing session at their convenience. This variation of the procedure established with the dance group was necessary because the control group volunteers were tested a few days after the treatment group and classes were by then beyond the "introductory" stage. Those that attended the testing session were reminded after taking the TSCS that they would be contacted about taking the survey a second time in eight weeks.

Posttest

During the eight-week treatment period the experimenter had no contact with experimental or control group subjects. At the end of this time subjects were contacted through their classes for posttesting. Dance group volunteers were again taken out of class for testing. (The dance 
teachers permitted this for the sake of experimental control.) Control group volunteers were given meeting times and places and again asked to report for testing at their convenience.

After taking the posttest, all subjects were given dates, times and locations for six debriefing sessions. They were told that if they wished they could stop in at any one of the sessions and pick up their test scores. They were also told that if interested they could get information concerning the test design and purpose. None of the treatment group volunteers returned to pick up their scores. Eight (24\%) persons of the original (men and women) control group collected their scores. Of the final nineteen women, five (26\%) returned to find out their scores.

Test Instrument

The Tennessee Self Concept Scale (TSCS) was used to obtain measures on the dependent variable. It was developed by William H. Fitts, Ph.D. and is described at length in the test manual. (Manual for the Tennessee Self Concept Scale, 1965) .

- Briefly, the TSCS is a self-administering, pencil-andpaper questionnaire consisting of 100 self-descriptive items. It is available in both a counseling and a clinical form and is appropriate for use with well-adjusted or disturbed persons over the age of twelve with at least a sixth-grade 
reading level. The Counseling Form contains five measures yielding 15 scores. It was used here because it is easily scored. In addition, it does not include measures for pathology and maladjustment as does the Clinical and Research form. It was thought that receiving those scores may have caused unnecessary stress to the subjects. Testtaking requires 10 to 20 minutes. The answer sheet may be hand scored or sent to the publisher for computer scoring. The test was standardized on a group of 626 people. Age ranged from 12 to 68 years; there were approximately equal numbers of both sexes and Black and white subjects. All social, economic, intellectual and educational (above sixth grade) levels were represented.

Test-retest reliability coefficients on all major scores are generally high. The highest (for the Counseling Form) was Total Positive (.92) while the lowest was Row Total Variability (.60). These scores signify, respectively, the total number of positive responses and the variability of responses across the five aspects of the self.

Validation procedures have been carried out for content validaty, discrimination between groups, correlation with personality measures and personality changes under particular conditions. In addition, Vacchiano and Strauss (1968) have completed a factor analytic study of construct validity for the TSCS and conclude that: "Although a complex measure, the scale does provide the five proposed 
measures. . when factors are considered together and thus lends some support to the validity of the test." (p. 326)

Treatment Condition

The three modern dance classes that functioned as the treatment condition were conducted by two different instructors. Instructor A held two of the classes, one Monday and Wednesday mornings at eight o'clock and one Tuesday and Thursday mornings at eight o'clock. Instructor B held the remaining class at Noon on Mondays and Wednesdays. In accordance with standards established by the Dance Department, both teachers required regular attendance in order to obtain a passing grade. The basic format of the three classes was atso the same. It consisted of a series of warm-up exercises designed to strengthen and loosen various muscle groups. These were followed by more complicated movement patterns, some stationary, some traveling, to build coordination. Neither instructor employed movement improvised by the students. Both instructors had one musician in attendance who provided music or rhythms (piano and drums) to accompany the dancers in their movement. It is hoped that the above similarities will have neutralized to some extent any influences that may have resulted from the instructors' personalities. 
Experimental Environment

The room used for the dance classes is located on the ground floor of the Health and Physical Education Building at Portland State University. It is a windowless room, 60-by-40 feet with a 14 to 15 foot ceiling. It has a wood floor and concrete walls. The east and west walls are cinder-block, painted white. The east wall features a mirror which begins at floor level and extends seven feet up the wall. The mirror runs the entire length of the wall. The north and south walls are gray concrete and have black steel bars approximately three-and-a-half feet from the floor. (These are used for stretching and warm-up exercises). The two primary entrances to the room are on the north wall. The most frequently used doorway is in the northwest corner. A second door in the northeast corner is also a possible entrance point but is infrequently used because it is sometimes blocked by a piano and cabinet which occupy that corner. In addition, there are two ancillary doors on the west wall which give access to a "wardrobe" room where paraphernalia for dance performances are stored. These doors are rarely used. There are two bulletin boards (west wall), a chalkboard and clock (north wall), and a gray metal box which encloses lighting controls used during studio performances (southwest corner). Finally, there are occasional chairs and a wooden bench along the west wall. 
As a rule, the room temperature varies throughout the day. It is usually a bit cool in the early morning (approximately $68^{\circ} \mathrm{F}$ ) and warmer $\left(72^{\circ}\right.$ to $75^{\circ} \mathrm{F}$ ) later in the day. This is determined by the time of year, the number of classes held in a given day and the general activity level. 


\section{CHAPTER III}

\section{RESULTS}

The experimental data were analyzed through the Academic Computing Services at Portland State University. This was accomplished by applying a program for an analysis of variance from the Statistical Package for the Social Sciences on the Harris 220 computer. Additional instructions in the specification field of the procedure card were employed to create an analysis of covariance. The data are presented in Table II. None of the posttest scores for the experimental group differed significantly from those for the control group. The only scores that approached a significant level were those for Identity at $\mathrm{P}$ 0.09. Therefore, the data do not support the hypothesis that technical training of dance-naive subjects over an eight week period results in measurable self concept change. 
MEAN SQUARES AND F SCORES ON

FOURTEEN SCALES OF THE TSCS

SOURCES OF VARIATION

Covariates Main Effects Explained Residual Total

\begin{tabular}{lllllll}
\hline TSCS Measures & df & 1 & 1 & 2 & 31 & 33
\end{tabular}

Self Criticism MS

$\mathrm{F}$

Significance

TOTAL P

MS

$\mathrm{F}$

Significance

Identity

MS

$\mathrm{F}$

Significance

Self Satisfaction MS

$\mathrm{F}$

Significance

Behavior

MS

F

Significance

Physical Self

MS

$\mathrm{F}$

Moral-Ethical Self

MS

F

Significance
Significance

34053.417

155.515

745.677

48.400

155.515

2726.040

86.547

6212.695

96.004

3527.869

136.494

0.336

0.013

0.910

176.171

2.722

0.109

2.721

0.177

0.677

452.461

2.066

0.161

96.589

3.067

0.090

0.910

1281.183

49.408

0.993

0.038

0.846

374.199

24.288

15.407

37.152

24.288

17252.939

78.791

218.9721251 .33

1411.315

44.807

$31.498 \quad 115.123$

3194.433

49.363

$64.713 \quad 254.393$

1764.102

68.253

$25.846 \quad 131.195$

641.088

24.723

25.931

63.213

94.319

1.056

132.651
1.485
0.232

132.651
1.485
0.232

55.987

0.627

1.880

0.078

0.782

1725.081

71.538

Significance

Family Self

MS

$\mathrm{F}$

Significance
1621.299

$56.65 \dot{3}$
49.653

1.735

0.197
$89.354 \quad 89.655$

$24.114 \quad 74.985$

35.808 
TABLE II (cont.)

MEAN SQUARES AND F SCORES ON

FOURTEEN SCALES OF THE TSCS

SOURCES OF VARIATION

Covariates Main Effects Explained Residual Total

\begin{tabular}{lllllll}
\hline TSCS Measures & df & 1 & 1 & 2 & 31 & 33
\end{tabular}

Social Self

MS

F

Significance

Total Variability

MS

$\mathrm{F}$

Significance

Column Variability

MS

F

Significance

Row Variability

MS

F

Significance

Distribution

MS

F

Significance

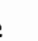

896.002

16.271

1832.325

30.889

1135.694

40.743

707.631

1.895

9538.941

17.024

1570.829

2.803

0.104

0.117

27.716

0.467

0.499

17.143

0.615

0.439

455.133

1.219

0.278
519.459

9.433

55.067

83.212

576.419

20.679

27.874

61.119

581.382

1.557

$373.467 \quad 386.068$

581.382

$373.467 \quad 863.030$

9.914

$50.320 \quad 112.090$ 15.678 


\section{CHAPTER FOUR}

\section{DISCUSSION}

Given the statistical results presented in Chapter Three, one must conclude that technical dance training does not produce significant change in self concept. The trend toward change that showed on the measure for Identity may warrant further study. Possibly the same experiment with a larger $\mathrm{N}$ would result in significant change on that factor. These results are the same as those obtained by Ludwig (1971). They are, however, quite different from these of Lofquist's (1979) study. A closer look at the three studies may reveal some of the factors which make dance therapy therapeutic.

The present study and Ludwig's are similar in many respects. In both experiments all treatment condition Ss were women and all were modern dance-naive. In addition, the mean ages for the two experimental groups were reasonably close; 19.2 years (Ludwig) and 21.1 years (this study). Both groups were enrolled in college level beginning modern dance classes and were drafted from those classes (as opposed to joining the classes as a condition of being in the experiment.) This fact might lead one to conclude that there would be no uniform motivational factor with respect to dance class enrollment. 
The control groups for both studies were also similar. Although mean ages were more disparate, 18.06 (Ludwig) and 23.8 years (present study), all were women and all were volunteers from lower division psychology classes. Control Ss in both studies were not involved in dance classes while the experiments were in progress. Additionally, control Ss in the present study were dance-naive. Ludwig did not state if such was the case in her control group.

Ludwig used the Interpersonal Checklist to measure self concept change in her experiment whereas the Tennessee Self Concept Scale was employed in the present study. It may well be that these two instruments measure self concept change differently and that one is more suited to research in dance. However, such a conclusion cannot be reached on the basis of the results of these studies.

While certain elements of the treatment conditions are the same in the two studies there are some important differences. Both conditions featured warm-up exercises and technical training (as described in Chapter Two of this study) and some kind of rythmical musical accompaniment. However, Ludwig's treatment condition also included improvisational movement which is not found in the present study. Improvisational, particularly expressive, movement is an integral part of many dance therapy programs (Rosen, 1957; Pesso, 1969; Alperson, 1974; Caplow-Lindner, et al., 1979), yet in the classroom context it does not appear to produce self 
concept change.

In comparing the present study with Lofquist's (1979), one finds numerous differences. Most striking is the fact that she records significant changes in self concept on three of the TSCS measures including the scale for Total Positive self concept. All of the changes were in a positive direction (i.e., scores were higher, indicating improved self concept. An explanation for such results may be found by examining subject population and treatment condition in Lofquist's study.

Lofquist's subjects were all women, as in the present study, but ages ranged from 35 to 62 years. The mean age of the control group was 46.3 years. Although some of Lofquist's subjects were college students, others were career women (either commercially or domestically). It is likely, given the age group, that those who were college students were also involved in career activities. Therefore, their reasons for joining the group were likely to be different from those of the subjects in the present study.

It is also possible that the initial self concepts of the experimental subjects in Lofquist's and the present study were different. If Lofquist's group entered the study with very low self esteem they would have had room for greater improvement than a group with already high self concept. The mean pretest scores of the dance condition subjects in the two studies are compared in Table III. They differ 
significantly only on the Personal Self Scale ( $\underline{t}=2.285$; p .05).

\section{TABLE III}

DANCE GROUP PRETEST MEANS:

A COMPARISON BETWEEN LOFQUIST'S AND THE PRESENT STUDY

\begin{tabular}{lrrr}
\multicolumn{1}{c}{ SCALE } & LOFQUIST'S & PRESENT STUDY & t-score \\
\hline Total Positive & 322.38 & 341.00 & 1.494 \\
Self Criticism & 39.19 & 37.40 & 1.032 \\
Identity & 118.25 & 123.87 & .903 \\
Self Satisfaction & 100.63 & 106.13 & .959 \\
Behavior & 104.13 & 111.00 & 1.802 \\
Physical & 62.75 & 64.33 & .571 \\
Moral-Ethical & 68.25 & 71.60 & 1.161 \\
Personal & 60.31 & 67.67 & $2.285 *$ \\
Family & 66.13 & 68.87 & 1.216 \\
Social & 64.63 & 68.33 & 1.208 \\
& & & \\
\hline
\end{tabular}

*Significant at $\mathrm{p} .05$.

Therefore, different experimental outcome cannot be credited to an initial disparity in self concept level between the two groups.

Lofquist used the TSCS to measure self concept change in her experiment; the same form as was employed in the present study. It must be concluded then, that the different outcomes of the two experiments are not a result of test instrument differences.

Lofquist's treatment condition was similar in some respects to that in the present study. However, certain aspects of the teacher-student relationship were very differ- 
ent. As in a conventional modern dance class, Lofquist employed warm-up exercises and movement sequences to strengthen muscles, increase flexibility and develop coordination. However, she used exercises and sequences typical of jazz dance. Jazz is a dance style that grew out of African Dance whereas modern dance is an approach to dance, a philosophy. It is possible that lessons in jazz dance would have a different effect on one's self concept than involvement in modern dance classes." Lofquist did not include free or creative movement as a part of her program.

The relationship that Lofquist developed with her students and the kind of feedback and verbalizations that she gave in class were very different from those in a typical dance technique class. Emphasis in technical training is on correcting errors ("Straighten your standing leg", "Align your hips and shoulders") with only a sprinkling of praise. IIn Lofquist's procedure praise and positive regard were of primary importance. Because she was working with older women she constantly stressed the importance of the exercises in relation to the aging process; emphasizing that staying fit helped one to look and feel younger. She encouraged a non-competitive atmosphere in which the participants might be able to perceive their bodies as strong and beautiful. Statements like "Look at your leg. It's the only leg you'll ever have. Isn't 
it beautiful?" are not typical of a standard dance technique class, but such statements were a prominent part of Lofquist's procedure.

It appears, then, that the results obtained by Lofquist are due to one or more of the following factors:

1. The age of her subjects.

2. The motivational level of her subjects.

3. The use of jazz style technique.

4. The positive and supportive atmosphere created by the teacher.

As regards the field of dance therapy, the first three factors seem less essential than the fourth. Dance therapy is done with people of all ages (Canner, 1968; Siegel, 1973; Caplow-Lindner, et al, 1979) and motivational levels (Pesso, 1969; Chace, 1975) and using a wide variety of movement styles (Salkin, 1973; Pesso, 1969; Chace, 1975). However, in no account of the practice of dance therapy is the supportive counselor-client relationship disregarded. Marian Chace (1975) observed that the dance therapist is not a teacher but a group leader who ". . combines verbal and nonverbal communication to enable a patient to express feeling, to participate in human relationships, to increase personal self esteem, to develop a more realistic concept of his body image, and through all of these to achieve some feeling of relaxation and enjoyment." (p. 144) 
Salkin (1973) notes that the dance therapist must relate to the client in an empathetic manner. This allows the therapist to be warm and personable while remaining objective.

Caplow-Lindner, Harpaz and Samberg (1979) reiterate the necessity for an empathetic, supportive group leader in the dance therapy situation. They also state that the dance therapist must respect the client, be flexible and able to respond to diverse needs, and be encouraging, cheerful and reassuring.

- It seems, then, that linking dance movement with an empathetic, supportive environment yields psychotherapeutic results. This particular study demonstrates that positive psychotherapeutic change is not a guaranteed outcome of participation in a dance technique class. However, one cannot conclude that change in self esteem never results from dance training. To do so is to flatly contradict the many observations of self concept change made by dancers and dance academicians (see pp. 12 to 18, this paper). Obviously, there is much research to be done yet in answering the questions surrounding dance as a psychotherapeutic tool. " However, this study, coupled with Ludwig's and Lofquist's workseems to have answered one important question. That is the one posed at the beginning of this paper: Is technical dance training alone enough $\partial$ 
to produce positive psychotherapeutic change? The answer, it appears, is: No, dance alone is not necessarily enough. 
Alperson, E.D. Carrying experiencing forward through authentic body movement. Psychotherapy: Theory, Research and Practice, 1974, 11(3), 211-214.

Boas, F. Dance and music in the life of the northwest coast indians of North America (Kwakiutl). In F. Boas (Ed.) The Function of Dance in Human Society, Brooklyn: Dance Horizons, 1944 .

Burton, C.L. Movement as group therapy in the psychiatric hospital. In K.C. Mason (Ed.) Focus on Dance:

Dance Therapy, Washington, D.C.: American Association for Health, Physical Education and Recreation, 1974, $7,19-23$.

Canner, N. . . . and a Time to Dance. Boston: Plays, Inc., 1968.

Caplow-Lindner, E., Harpaz, L. and Samberg, S. Therapeutic Dance/Movement: Expressive Activities for Older Adults. New York: Human Sciences Press, 1979 .

Chace, M. (Collected writings) In H. Chaiklin (Ed.), Marian Chace: Her Papers. Columbia, Md.: American Dance Therapy Association, 1975.

Duncan, C.B. A reputation test of personality integration. Journal of Personality and Social Psychology, $1966,3(5), 516-524$.

Fitts, W.H. The self concept and psychopathology. Studies on the Self Concept, 1972, No. 4.

Fitts, W.H. The self concept and self-actualization. Studies on the Self Concept, 1971, No. 3 .

Fitts, W.H. Tennessee Self Concept Scale. Nashville: Counselor Recordings and Tests, 1965.

Fleming, G.A. Creative Rhythmic Movement. New Jersey: Prentice Hall, 1976.

Gorer, G. Functions of dance forms in primitive African communities. In F. Boas (Ed.) The Function of Dance in Human Society, Brooklyn: Dance Horizons, 1944 . 
Gross, W.F. and Alder, L.O. Aspects of alcoholics' self concepts as measured by the Tennessee Self Concept Scale. Psychological Reports, 1970, 27, 431-434.

Gunning, S.V. and Holmes, T.H. Dance therapy with psychotic children. Archives of General Psychiatry, $1973,28,707-713$.

Hall, C.S. and Lindzey, G. Theories of Personality. New York: John Wiley and sons, 1970.

Hann, V.L. A comparison of experienced modern dancers to non-dancers in self image, body image, movement concept and kinesthetic arm positioning. (Master's Thesis, Washington State University) University of Oregon Microfilms, 1973, No. 75-116.

H'Doubler, M. Dance: A Creative Art Experience. Madison: University of Wisconsin Press, 1962.

Horst, L. and Russell, C. Modern Dance Forms. Brooklyn: Dance Horizons, 1967. (Originally pubIished: San Francisco: Impulse Publications, 1961).

Humphrey, D. The Art of Making Dances. New York: Grove Press, Inc., 1959.

James, W. Principles of Psychology. Dover Publications, 1890 .

Koner, P. Intrinsic dance. In S.J. Cohen (Ed.), The Modern Dance: Seven Statements of Belief, Connecticut: Wesleyan Press, 1965, 77-89.

Kraus, R. History of the Dance. Englewood Cliffs, NJ: Prentice-Hall, Inc., 1969.

Langer, S.K. Virtual powers. In M.H. Nadel and C.G. Nadel (Eds.), The Dance Experience, New York:

Prager Publishers, 1970 .

Lawton, S.U. Dance as therapy. In A. Chujoy (Ed.), The Dance Encyclopedia, New York: A.S. Barnes \& Co., 1949, pp. 134-139.

Levy, L.L. Movement therapy for psychiatric patients. American Journal of Occupational Therapy, 1974, 28(6), 354-357. 
Lofquist, T. Dance therapy in an experimental model. Unpublished master's thesis, Portland State University, 1979.

Ludwig, A.B. An evaluation of modern dance as an educational process incorporating physical, creative and psychological changes within the individual. (Master's Thesis, University of Kansas) University. of Oregon Microflims, 1971, No. 73-332.

Martin, J. Introduction to the Dance. New York: Dance Horizons, 1965.

Maslow, A.H. Motivation and Personality. New York: Harper \& Row, 1954 .

McPartland, T.S., Cumming, J.H. and Garretson, N.S. Self conception and ward behavior in two psychiatric hospitals. Sociometry, 1961, 24, 111-124.

Meerlo, J.A.M. Dance Craze and Sacred Dance, London: Peter Owen, Limited 1962.

Pesso, A. Movement in Psychotherapy. New York: New York University Press, 1969.

Raimy, V. The Self Concept as a Factor in Counseling and Personality Organization, The Ohio University Libraries, 1971.

Robinson, L.D. A program for deaf mental patients, Hospital and Community Psychiatry, 1973, 24(1), 40-42.

Rogers, C.R. On Becoming a Person. Boston: Houghton Mifflin Company, 1961.

Rosen, E. Dance in Psychotherapy. New York: Columbia University, 1957.

Salkin, J. Body Ego Technique. Illinois: Charles C. Thomas, $197 \overline{3}$.

Sandel, S.L. Integrating dance therapy into treatment. Hospital and Community Psychiatry, 1975, 26(7), 439441 .

Schilder, P. The Image and Appearance of the Human Body. New York: International Universities Press, 1950. 
Schmais, C. Dance therapy in perspective. In K.C. Mason (Ed.) Focus on Dance: Dance Therapy, Washington, D.C.: American Association for Health, Physical Education and Recreation, 1974, 7, 7-12.

Schoop, T. Won't You Join the Dance? Mayfield Publishing Co., $19 \overline{74 .}$

Secourd, P.F. and Jourard, S.M. The appraisal of bodycathexis: body-cathexis and the self. Journal of Consulting Psychology, 1953. 17(3), 343-347.

Seeman, J. Personality integration in college women. Journal of Personality and Social Psychology, 1966, 4(1), 91-93.

Siegel, E.V. Movement therapy as a psychotherapeutic tool. American Psychoanalytic Association Journal, $1973,2 \overline{1(2), 333-343 .}$

Snygg, D. and Combs, A.W. Individual Behavior. New York: Harper, 1949.

Sokolow, A. The rebel and the bourgeois. In S.J. Cohen (Ed.) The Modern Dance: Seven Statements of Belief, Connecticut: Wesleyan Press, 1965, 29-37.

Thomas, M. and Seeman, J. Criterion measures for therapy outcome: A study in personality integration. Psychotherapy: Theory, Research and Practice, 1971, $8(1), 26-30$.

Tolor, A., Cramer, M., D'Amico, D. and O'Marra, M. The effects of self concept, trust and imagined positive or negative self disclosure on psychological space. The Journal of Psychology, 1975, 39, 9-24.

Vacchiano, R.B. and Strauss, P.S. The construct validity of the Tennessee Self Concept Scale. Journal of Clinical Psychology, 1968, 24(2), 323-326.

Zion, L.C. Body concept as it relates to self concept. The Research Quarterly, 1965, 36(4), 490-495. 


\section{APPENDIX}

TENNESSEE SELF CONCEPT SCALE 


\section{TEN NESSEE \\ SELF CONCEPT SCALE}

by

William H. Fitts, PhD.

Published by

Counselor Recordings and Tests

Box 6184 - Acklen Station

Nashville, Tennessee 37212 
1. I have a heal thy body

3. I am an attractive person

5. I consider myself a sloppy person.

19. I am a decent sort of person.

21. I am an honest person.

23. I am a bad person

37. I am a cheerful person

39. I am a calm and easy going person.

41. I am a nobody

55. I have a family that would always help me in any kind of trouble

57. I am a member of a happy family

59. My friends have no confidence in me

73. I am a friendly person

75. I am popular with men

77. I am not interested in what other people do

91. I do not always tell the truth.

93. I get angry sometimes

Completely Mostly false

$$
\text { false }
$$

Partly false and partly true
Mostly true

Completely true 5 
2. I like to look nice and neat all the time

4. I am full of aches and pains.

6. I am a sick person

20. I am a religious person

22. I am a moral failure.

24. I am a morally weak person

38. I have a lot of self-control

40. I am a hateful person.

42. I am losing my mind.

56. I am an important person to my friends and family.

58. I am not loved by my family

60. I feet that my family doesn't trust me.

74. I am popular with women.

76. I am mad at the whole world.

78. I am hard to be friendly with

92. Once in a while $I$ think of things too bad to talk about

94. Sometimes, when 1 am not feeling well, 1 am cross.

Completely Mostly false

1 false

2
Partly false and partly true
Mostly Completely

true true 
7. I am neither too fat nor too thin.

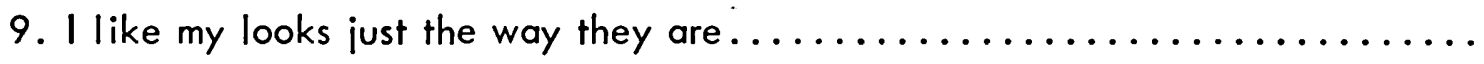

11. I would like to change some parts of my body.

25. I am satisfied with my moral behavior.

27. I am satisfied with my relationship to God.

29. I ought to go to church more

43. I am satisfied to be just what I am

45. I am just as nice as I should be

47. I despise myself

61. I am satisfied with my family relationships.

63. I understand my family as well as I should.

65. I should trust my family more

79. I am as sociable as I want to be

81. I try to please others, but I don't overdo it

83. I am no good at all from a social standpoint

95. I do not like everyone I know.

97. Once in a while, I laugh at a dirty joke.

ResponsesCompletely Mostly Partly false Mostly Completely false false and true true partly true 
8. I am neither too tall nor too short.

10. I don't feel as well as I should

12. I should have more sex appeal

26. I am as religious as I want to be

28. I wish I could be more trustworthy

30. I shouldn't tell so many lies.

44. I am as smart as I want to be

46. I am not the person I would like to be

48. I wish I didn't give up as easily as I do

62. I treat my parents as well as I should (Use past tense if parents are not living)

64. I am too sensitive to things my family say.

66. I should love my family more...

80. I am satisfied with the way I treat other people.

82. I should be more polite to others.

84. I ought to get along better with other people.

96. I gossip a little at times.

98. At times I feel like swearing

\begin{tabular}{|c|c|c|c|c|c|}
\hline Responses - & $\begin{array}{c}\text { Completely } \\
\text { false }\end{array}$ & $\begin{array}{c}\text { Mostly } \\
\text { false }\end{array}$ & $\begin{array}{l}\text { Partly false } \\
\text { and } \\
\text { partly true }\end{array}$ & $\begin{array}{l}\text { Mostly } \\
\text { true }\end{array}$ & $\begin{array}{c}\text { Completely } \\
\text { true }\end{array}$ \\
\hline
\end{tabular}


13. I take good care of myself physically.........................

15. I try to be careful about my appearance................... 15

17. I often act like I am "all thumbs" .................... 17

31. I am true to my religion in my everyday life $\ldots \ldots \ldots \ldots \ldots \ldots \ldots$

33. I try to change when $\mid$ know $\mid$ 'm doing things that are wrong......... 33

35. I sometimes do very bad things...................... 35

49. I can always take care of myself in any situation ............... 49

51. I take the blame for things without getting mad.............. 51

53. I do things without thinking about them first............... 53

67. I try to play fair with my friends and family................ 67

69. I take a real interest in my family...................... 69

71. I give in to my parents. (Use past tense if parents are not living).......

85. I try to understand the other fellow's point of view

87. I get along well with other people $\ldots \ldots \ldots \ldots \ldots \ldots \ldots \ldots \ldots \ldots$

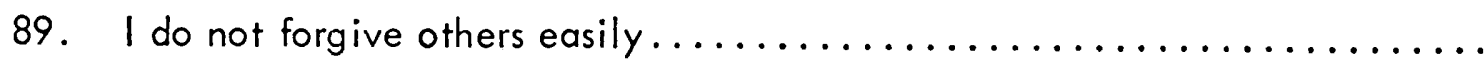

99. I would rather win than lose in a game $\ldots \ldots \ldots \ldots \ldots \ldots \ldots \ldots$

\begin{tabular}{|c|c|c|c|c|}
\hline Responses - & $\begin{array}{c}\text { Completely } \\
\text { false }\end{array}$ & $\begin{array}{l}\text { Mostly } \\
\text { false }\end{array}$ & $\begin{array}{c}\text { Partly false } \\
\text { and }\end{array}$ & $\begin{array}{c}\text { Completely } \\
\text { true }\end{array}$ \\
\hline
\end{tabular}

$\begin{array}{lllll}1 & 2 & 3 & 4\end{array}$


14. I feel good most of the time

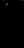

16. I do poorly in sports and games

18. I am a poor sleeper

32. I do what is right most of the time

34. I sometimes use unfair means to get ahead

36. I have trouble doing the things that are right

50. I solve my problems quite easily

52. I change my mind a lot

54. I try to run away from my problems

68. I do my share of work at home

70. I quarrel with my family

72. I do not act like my family thinks I should

86. I see good points in all the people I meet

88. I do not feel at ease with other people

90. I find it hard to talk with strangers

100. Once in a while I put off until tomorrow what l ought to do today

\begin{tabular}{|c|c|c|c|c|c|}
\hline Responses- & $\begin{array}{c}\text { Completely } \\
\text { false }\end{array}$ & $\begin{array}{l}\text { Mostly } \\
\text { false }\end{array}$ & $\begin{array}{l}\text { Partly false } \\
\text { and } \\
\text { partly true }\end{array}$ & $\begin{array}{l}\text { Mostly } \\
\text { true }\end{array}$ & $\begin{array}{c}\text { Completely } \\
\text { true }\end{array}$ \\
\hline & 1 & 2 & 3 & 4 & 5 \\
\hline
\end{tabular}

